\section{CORAT: A FORTRAN subroutine to calculate orthogonal coefficients for trend analysis}

\author{
CAMILLE-AIMÉ POSSAMAÏ \\ Institut de Neurophysiologie et de Psychophysiologie, C.N.R.S. \\ Marseills, France'
}

Several authors, e.g., Edwards (1968) and Lewis (1960), have shown the usefulness of the trend analysis for many problems in psychological research. Trend analys is is easily performed when the levels of the independent variable are equally spaced and when the number of observations at each level is the same. because in this case the orthogonal coefficients which allow the calculation of sums of squares and regression coefficients for all components (up to the fifth order) have been tabled (Fisher \& Yates, 1957). In the other cases, one must calculate the orthogonal coefficients which is generally laborious. Gaito (1965) provides a technique for easy calculation of coefficients for linear and quadratic components, and Stang and O'Connell (1973) report a DEC-10 system subroutine which makes use of it. The technique described by Gaito may be generalized to all components.

Let $X_{j}$ be the values of the independent variable for the $j$-th group and $\gamma_{k j}$ the orthogonal coefficients for component $k$ and group $j$. Then:

$$
\begin{aligned}
& \gamma_{\mathrm{k} 1}=a_{\mathrm{k} 1}+a_{\mathrm{k} 2} \mathrm{X}_{1}+\ldots \ldots \ldots a_{\mathrm{kk}} \mathrm{X}_{1}^{\mathrm{k}-1}+\mathrm{X}_{1}^{\mathrm{k}} \\
& \gamma_{\mathrm{k} 2}=a_{\mathrm{k} 1}+a_{\mathrm{k} 2} \mathrm{X}_{2}+\ldots \ldots \ldots a_{\mathrm{kk}} \mathrm{X}_{2}^{\mathrm{k}-1}+\mathrm{X}_{2}^{\mathrm{k}} \\
& - \\
& - \\
& \gamma_{\mathrm{kn}}=a_{\mathrm{k} 1}+a_{\mathrm{k} 2} \mathrm{x}_{\mathrm{n}}+\ldots \ldots \ldots a_{\mathrm{kk}} \mathrm{X}_{\mathrm{n}}^{\mathrm{k}-1}+\mathrm{X}_{\mathrm{n}}^{\mathrm{k}}
\end{aligned}
$$

Because of the conditions of orthogonality

$$
\begin{array}{ll}
\Sigma n_{j} \gamma_{k j}=0 & V_{k} \\
\Sigma n_{j} \gamma_{k j} \gamma_{1 j}=0 & V_{k}, V_{1}, k \neq 1
\end{array}
$$

Where $n_{j}$ is the number of observations in the group $j$, it follows that the as necessary to calculate the $\gamma_{k} s$ are the solutions of the set of equations the coefficients of which are:

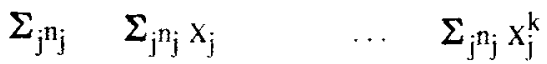

$$
\begin{aligned}
& \begin{array}{llll}
0 & \boldsymbol{\Sigma}_{\mathrm{j}} \mathrm{n}_{\mathrm{j}} \gamma_{1 \mathrm{j}} \mathrm{X}_{\mathrm{j}} \quad \ldots \quad \boldsymbol{\Sigma}_{\mathrm{j}} \mathrm{n}_{\mathrm{j}} \gamma_{1 \mathrm{j}} \mathrm{X}_{\mathrm{j}}^{\mathrm{k}}
\end{array}
\end{aligned}
$$

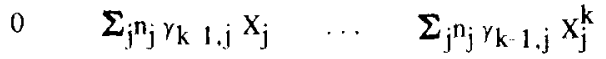

Then, by replacing as in Equations 1, one obtains the orthogonal coefficients for the $\mathbf{k}$-th order component.

Description of the program. Subroutine CORAT generates and returns the orthogonal polynomials for all components, depending on the number of degrees of freedom. First, it calculates the values $\Sigma_{n_{j}}$ and $\Sigma_{n_{j}} X_{j}$, which permit it to generate the first polynomial

This work was done as a complement of a predoctoral dissertation at the University of Aix-Marseille 11. The author wishes to thank M. F. Vaissière and G. Reynard for their kind help. and which are kept in a row-matrix. Then, in order to generate a polynomial, it is only necessary to add one row and one column to the matrix formerly used to generate the previous one.

language and computer. The program was written in FORTRAN IV and developed on UNIVAC 1110. The calculation of the as requires a subroutine to find the solutions to a set of equations.

Accuracy. CORAT has been tested with a short driving main program which seltected randomly the number of groups, the value of the independent variable for each group, and the number of observations per group. It has also been tested in the equal interval and equal number of observations case. In the latter case, the orthogonality of the coefficients is very good up to the fifth-order component. In the former ease, marked departures from orthogonality have been found, especially for high-order components, when the levels of the independent variable were very unequally spaced and when the number of observations at each level was very different. However. in the usual work, at least, the coefficients for the linear, the quadratic, and the cubic components are reasonably gond.

Purpose. To calculate the orthogonal coefficients for trend analysis in the general case with unequal intervals and unequal number of observations per group.

Call List. In the main program, one must have the following statements.

DIMENSION G (N,N), I (N, N), X (N), A (N, N), IE (N), TMI 1 (N. N), TM2 (N. 1), TL (N)

.

CALL CORAT (X, IE, A, G, T, TM1, TM2, TL, IN, N)

where $X$ contains the values of the independent variable: IE contains the number of observations at each level of the independent variable; $\mathrm{N}$ is the maximum number of levels of the independent variable; IN is the actual number of levels of the independent variable; $A, G, T, T M 1$, and TM2 are arrays used in CORAT; and TL is an array used in MXSIMQ, which is a subroutine called in CORAT (see below).

Requirements. A subroutine to calculate the solutions of a set of simultancous equations is required. The first members are in MATl, the second ones in MAT2. In our program, this subroutine is MXSIMQ (associated with MXFREE). It uses the array $\mathrm{L}$ and requires two dimensions for MAT2. Obviously, with another subroutine, L could be suppressed and MAT2 could have just one dimension. MXSIMQ returns the solutions in MAT1; with another subroutine, the DO LOOP 500 should be modified as necessary.

Output. This sequence of program:

CALL CORAT (X, IE, A, G, T, TM1, TM2, TL, IN, N) INM $1=:=$ IN -1

DO $100 \quad I=1$, INM I

100

PRINT 1, (G(I.J), J =- 1. IN)

prints:

$\begin{array}{lllll}r_{11} & r_{12} & r_{13} & \ldots \ldots \ldots & r_{1, \mathrm{~N}} \\ r_{21} & r_{22} & r_{23} & \ldots \ldots \ldots & r_{2, \mathrm{IN}} \\ r_{\mathrm{N} 1,1} & r_{\mathrm{N} 1,2} & r_{N 1,3} & & r_{N 1, \mathrm{~N}}\end{array}$

Availability. A write-up for use and a FORTRAN IV listing may be obtained by writing to Camille-Aimé Possamaï, C.N.R.S.I.N.P.4, 31, chemin J. Aiguier, 13274. Marseille, Cedex 2, France.

\section{REFERENCES}

EDwards, A. L. Experimental' design in psychological research. New York: Holt. Rinehart and Winston, 1968. 
Fisher. R. A., d Yates. F. Statistical table's for biological. agricultural and modical research. New York: Hafner. 1957.

GAïto. J. Unequal intervals and unequal $n$ in trend analysis. Psyehologicul Bulletin. 1965. 63. 125-127.

\section{GRADEM: A FORTRAN IV program for maintaining the student gradebook}

\author{
MARLENE D. ROTH and DAVID J. STANG \\ Queens College of the City Universing of New York \\ Flushing. New York 11367
}

Entering grades in a gradebook, calculating each student's average grade, and posting these grades for feedback to students can be an extremely tedious and time-consuming task. particularly in large classes or in classes with many grades on projects and quizzes. Errors are quite often made, and their correction is bothersome and time-consuming to both teacher and student. GRADEM is a program designed to facilitate the calculation and posting of students grades. The grades can be posted during the term to allow each student to see how well he is doing. Since the grades are recorded according to the students identification number. only the student and the professor need know the grades. Posting the grades in this manner also permits the student to determine his relative class standing. and provides incentive to improve his standing.
Lewis, D. Quanitative methods in psychology. New York: Mc Graw-Hili. 1960$)$.

Stang. D. J., \& O'Connell, E. J. TREND: A FORTRAN IV subroutine for trend analysis, Behavioral Science. 1973. 18. 77.

Input. For each test: (1) a title card which contains the number of students who have taken that test. the number of questions on that test. and the name of the test: (2) one card for each student who took the test. containing the student's identitication number and test grade.

Output. (1) Class and other identification; (2) test titles and descriptions: (3) the sum (or average) of the students grades in descending order with each student's test marks and identification number.

Computer and language. This program was written on the Xerox Sigma 7 . and will run on any Xerox computer. With some slight alterations to the code. this program will run on any computer that supports FORTRAN. The maximum core requirement is $5 K$, and the total job time is well under $1 \mathrm{~min}$.

Restrictions. The maximum number of students allowed is 200 . and the nuximum number of tests is 15 (although both can be expanded, if needed, by minimal alteration of the code). If the latter alteration is made, the format of the output must also be changed to allow for the printing of the identitication number. the test grades. and the sum (or average) of the grades on one line.

Availability. A copy of the listing. documentation. and sample output can be obtained free of charge by writing David Stang. Department of Psychology, Queens College of the City University of New York, Flushing. New York 11367. 